Pediat. Res. 6: 514-520 (1972)

Chromosomal aberrations lymphocytes

fibroblasts radiosensitivity,

karyotype chromosomal

\title{
In Vitro Chromosomal Radiosensitivity in Patients and in Carriers with Abnormal non-Down's Syndrome Karyotypes
}

\author{
Makoto Higurashi ${ }^{[261}$ and Patriak E. Conen \\ Department of Pathology and The Research Institute, The Hospital for Sick Children, and \\ The University of Toronto, Toronto, Ontario, Canada
}

\begin{abstract}
Extract
This paper reports in vitro tests of chromosomal radiosensitivity in five children and three adults with normal karyotypes as control subjects, in seven patients (children) with chromosomal abnormalities, and in six translocation carriers (adults). Peripheral blood samples from each individual and skin fibroblast cultures from four children in the control group, five patients with chromosomal abnormalities, and one translocation carrier were irradiated with 10 and 100 rads. Nonirradiated duplicate cultures were used as controls. Blood cultures were harvested after $52 \mathrm{hr}$ of incubation and fibroblast cultures were harvested $24 \mathrm{hr}$ after irradiation. The frequency of chromosomal breakage caused by irradiation was calculated by subtracting the values for nonirradiated samples from those for irradiated samples. In normal control subjects, the number of chromosome-type breaks per cell per rad was $0.0024 \pm$ 0.0009 and $0.0020 \pm 0.0009$ in lymphocytes of children and adults, respectively, and $0.0049 \pm 0.0021$ in fibroblasts of children. The number of breaks per cell per rad was $0.0055 \pm 0.0017$ in lymphocytes and $0.0082 \pm 0.0013$ in fibroblasts of patients, and $0.0040 \pm 0.0018$ in lymphocytes and $0.0063 \pm 0.0017$ in fibroblasts of carriers. In comparison with age-matched controls, significantly elevated frequencies of breaks per cell per rad were observed in cultured lymphocytes and fibroblasts of patients, and in cultured lymphocytes of translocation carriers (Table II). After irradiation with 100 rads, the number of dicentrics and rings per cell was significantly greater in both patients and carriers of chromosomal abnormalities than in control subjects (Tables I and III). Therefore, chromosomes of cells of patients with chromosomal abnormalities and of translocation carriers were significantly more radiosensitive in vitro than those of control subjects.
\end{abstract}

\section{Speculation}

Patients with chromosomal abnormalities and carriers with a translocated chromosome show greater chromosomal changes after irradiation in all age groups than do normal control subjects. These individuals, therefore, should be subjected to as little $\mathrm{x}$-ray examination as possible. 


\section{Introduction}

Patients with Down's syndrome (trisomy 21) and perhaps patients with other chromosomal abnormalities have an increased risk of malignancy $[4,8,10,12-14$, 20]. Recently it has been reported that fibroblasts from patients with Down's syndrome, E syndrome, Bloom's syndrome, and Fanconi's anemia are more susceptible to transformation by Simian virus 40 (SV40) in vitro [18].

These findings suggest that cells with chromosomal abnormalities have a particularly high sensitivity to mutagenic agents and to the noxious effects of external environment. Such sensitivity might shed light on the relation between the genetic background of cells with chromosomal abnormalities and the susceptibility of the cell to cancer.

In this paper, the in vitro effects of radiation on cultured lymphocytes and fibroblasts from patients with various types of chromosomal abnormalities and from carriers with translocated chromosomes are reported and compared with the effects found in normal control subjects.

\section{Materials and Methods}

Lymphocytes and fibroblast cultures from 21 subjects [22] were investigated (Table $\mathrm{I}$ ): five children and three adults with normal karyotypes [23]; seven patients with chromosomal abnormalities (three with trisomy 21 and one each with trisomy $\mathrm{D}_{1}$, short arm deletion B4, short arm deletion $\mathrm{B} 5$, and a ring $\mathrm{B}$ ); and six carriers with balanced translocations (two with Al/D and four with Al/A2) [24]. The group of children used as control subjects in this study included a 2-wkold baby with a normal karyotype in addition to the control subjects described in our previous paper on Fanconi's anemia [9]. None of the subjects had a past

Table I. Chromosomal aberrations in lymphocytes after irradiation ${ }^{1}$

\begin{tabular}{|c|c|c|c|c|}
\hline & No. of subjects & $\begin{array}{l}\text { No. of cells } \\
\text { examined }\end{array}$ & No. of del/c ${ }^{2}$ & No. of $\mathrm{D}+\mathrm{R} / \mathrm{c}^{3}$ \\
\hline \multicolumn{5}{|l|}{ Exposed to 10 rads } \\
\hline Controls for children & 5 & 350 & $0.018 \pm 0.011$ & 0 \\
\hline Controls for adults & 3 & 300 & $0.014 \pm 0.006$ & 0 \\
\hline $\begin{array}{l}\text { Chromosomal abnormalities with abnormal } \\
\text { phenotypes }\end{array}$ & 7 & 560 & $0.033 \pm 0.016$ & $0.006 \pm 0.007$ \\
\hline Trisomy $\mathrm{D}_{1}$ & $\mathrm{I}$ & 100 & 0.005 & 0 \\
\hline Trisomy 21 & 3 & 246 & $0.005 \pm 0.008$ & $0.026 \pm 0.012$ \\
\hline B4 short arm deletions & 1 & 52 & 0.044 & 0.019 \\
\hline Cri-du-Chat & 1 & 62 & 0.048 & 0 \\
\hline $\mathrm{B}$ ring & 1 & 100 & 0.008 & 0.01 \\
\hline Translocation carriers & 6 & 362 & $0.018 \pm 0.008$ & $0.002 \pm 0.004$ \\
\hline $\mathrm{Al} / \mathrm{D}^{4}$ & 2 & 117 & $0.010 \neq 0.008$ & 0 \\
\hline $\mathrm{A} 1 / \mathrm{A}^{5}$ & 4 & 245 & $0.026 \pm 0.012$ & $0.003 \pm 0.005$ \\
\hline \multicolumn{5}{|l|}{ Exposed to 100 rads } \\
\hline Controls for children & 5 & 350 & $0.124 \pm 0.010$ & $0.084 \pm 0.010$ \\
\hline Controls for adults & 3 & 300 & $0.120 \pm 0.030$ & $0.060 \pm 0.016$ \\
\hline $\begin{array}{l}\text { Chromosomal abnormalities with abnormal } \\
\text { phenotypes }\end{array}$ & 7 & 558 & $0.135 \pm 0.020$ & $0.259 \pm 0.027^{6}$ \\
\hline Trisomy $\mathrm{D}_{1}$ & 1 & 100 & 0.130 & 0.280 \\
\hline Trisomy 21 & 3 & 244 & $0.126 \pm 0.013$ & $0.233 \pm 0.015$ \\
\hline B4 short arm deletions & 1 & 56 & 0.141 & 0.304 \\
\hline Cri-du-chat & 1 & 58 & 0.173 & 0.241 \\
\hline B ring & 1 & 100 & 0.138 & 0.280 \\
\hline Translocation carriers & 6 & 443 & $0.147 \pm 0.019$ & $0.201 \pm 0.057^{6}$ \\
\hline $\mathrm{Al} / \mathrm{D}^{4}$ & 2 & 118 & $0.152 \pm 0.031$ & $0.215 \pm 0.014$ \\
\hline $\mathrm{A} 1 / \mathrm{A} 2^{5}$ & 4 & 325 & $0.144 \pm 0.019$ & $0.194 \pm 0.079$ \\
\hline
\end{tabular}

1 The spontaneous background of chromosomal aberrations has been subtracted.

$2 \mathrm{del} / \mathrm{c}$ : deletions per cell.

${ }^{3} \mathrm{D}+\mathrm{R} / \mathrm{c}$ : dicentrics and rings per cell.

$46, X X, t(1 \mathrm{q}+: \mathrm{Dq}-)$.

$646, X X, t(1 q+: 2 q-)$ and $46, X Y, t(1 q+: 2 q-)$.

${ }^{6}$ Significant difference $(P<0.01)$. 
history of heavy irradiation exposure or recent viral infections.

Each blood sample was divided into three 2-ml portions: one portion was used as a nonirradiated control, one was irradiated with 10 rads and one with 100 rads. The samples were cultured for $52 \mathrm{hr}$, including a terminal 4-hr treatment with colchicine by a modified method of Moorhead et al. [15]. Many mitoses were required for the estimation of chromosomal damage; occasionally, cultures were repeated two or three times in order to obtain sufficient numbers of mitoses.

Fibroblast cultures were made from skin samples taken from the forearms of patients and carriers. In control subjects, samples were obtained from inguinal or abdominal incisions during operations rather than from incisions in the forearm, because the latter surgical procedures are relatively infrequent. Cultures were initiated by use of a double coverslip method [2] and were examined as soon as growth was sufficient. These cultures were also divided into three portions: one was used as a nonirradiated control and the other two were irradiated, one with 10 rads and one with 100 rads, $24-48 \mathrm{hr}$ after subculture. Fibroblasts were harvested $24 \mathrm{hr}$ after irradiation.

Plastic tubes containing blood and fibroblast cultures (at room temperature) were exposed to $\gamma$ rays at a dose rate of 94.9 rads/min emitted from an experimental ${ }^{137} \mathrm{Cs}$ unit [5]. The rate for each lower dose irradiation was measured with a dosimeter [21].

Cells in mitosis were located by scanning at low magnification, and unbroken cells with well defined chromosomal morphology at high magnification were used for detailed study. Because patients were not available at the same time, coding of slides was unsuccessful and cytologic studies were made whenever preparations were ready. All cells were studied by direct microscopic examination. The microscope stage position of the cell was recorded as well as chromosome count and presence of aberrations. All cells in which a chromosomal abnormality was recognized were photographed for complete karyotype or analyses of the prints. In order to study overlapping chromosomes, drawings were made of parts of some metaphases. In all test and control cultures, 100 metaphases were studied; when this was not possible, all suitable cells (minimum: 50 cells/culture) were examined.

The following structural chromosome-type aberrations were recorded and used in calculations: dicentrics, rings, acentrics and minute acentrics, deletions, and multicentrics. It was assumed that each dicentric and ring always appeared with its associated acentric chromosome; therefore the acentric and minute acentric chromosomes were classified into two categories: (1) acentrics produced as counterparts of dicentrics or rings, and (2) acentrics which were deletions that occurred independently of such dicentrics or rings. Only the latter type of acentric was used in calculation of deletions per cell. Rare multicentric chromosomes, i.e., with three or more centromeres, were scored as dicentrics (the number of centromeres $-1=$ dicentric equivalent).

The following abnormalities were not used for calculation: (1) chromatid breaks and gaps or visual discontinuities of chromatin without displacement were separately recorded but both were excluded from calculations because they are not useful in radiation studies [6]; and (2) symmetrical exchanges were also excluded because they were not easy to detect by direct microscopic examination.

The number of chromosome-type breaks per cell was obtained by adding the number of chromosome deletions and twice the number of two-hit aberrations (dicentrics and rings), and then dividing by the number of cells examined. The numbers of deletions per cell and of dicentrics and rings per cell were obtained by dividing the number of aberrations observed by the number of cells examined. Figures per cell per rad were obtained by dividing the aberration number per cell by the radiation dose.

The frequencies of chromosomal aberration induced by irradiation were calculated by subtracting values for nonirradiated samples from those for irradiated samples. Only the radiation-induced aberration figures are shown in Tables I-III. By standard statistical techniques, particularly the $t$-test, the significance of chromosomal changes were estimated using tables of probability values.

\section{Results}

\section{Chromosomal Aberrations in Nonirradiated Lympho- cytes}

The number of chromosomal breaks including chromatid-type breaks in cultures from patients with chromosomal abnormalities and from balanced translocation carriers was not significantly greater than that for control subjects. Few chromosome-type aberrations such as chromosome deletion, dicentrics and rings were found for patients with chromosomal abnormalities, balanced translocation carriers, and control subjects. 
Table II. The number of breaks per cell per $\operatorname{rad}^{1}$

\begin{tabular}{|c|c|c|c|c|c|}
\hline & $\begin{array}{l}\text { No. of } \\
\text { subjects }\end{array}$ & Age & $\begin{array}{l}\text { No. of cells } \\
\text { examined }\end{array}$ & No. of breaks $/ \mathrm{c} / \mathrm{r}$ & $i$ test \\
\hline \multicolumn{6}{|l|}{ Lymphocytes } \\
\hline Controls for children & 5 & $2 \mathrm{wk}-12 \mathrm{yr}$ & 700 & $0.0024 \pm 0.0009$ & \\
\hline Controls for adults & 3 & $20-32$ yr & 600 & $0.0020 \pm 0.0009$ & \\
\hline $\begin{array}{l}\text { Chromosomal abnormalities with abnormal } \\
\text { phenotypes }\end{array}$ & 7 & & 1118 & $0.0055 \pm 0.0017$ & $P<0.01$ \\
\hline Trisomy $D_{1}$ & 1 & $2 \mathrm{mo}$ & 200 & $0.0060 \pm 0.0013$ & \\
\hline Trisomy 21 & 3 & $3 \mathrm{mo}-1 \mathrm{yr}$ & 490 & $0.0045 \pm 0.0016$ & \\
\hline B4 short arm deletion & 1 & $2 \mathrm{mo}$ & 108 & $0.0079 \pm 0.0006$ & \\
\hline Cri-du-Chat & 1 & $6 \mathrm{mo}$ & 120 & $0.0057 \pm 0.0013$ & \\
\hline$B$ ring & 1 & $6 \mathrm{yr}$ & 200 & $0.0049 \pm 0.0029$ & \\
\hline Translocation carriers & 6 & & 805 & $0.0040 \pm 0.0018$ & $0.02>P>0.01$ \\
\hline $\mathrm{Al} / \mathrm{D}^{2}$ & 2 & $27-30 \mathrm{yr}$ & 235 & $0.0040 \pm 0.0014$ & \\
\hline $\mathrm{Al} / \mathrm{A}^{3}$ & 4 & $26-69$ yr & 570 & $0.0041 \pm 0.0015$ & \\
\hline \multicolumn{6}{|l|}{ Fibroblasts } \\
\hline Controls for children & 4 & & 700 & $0.0049 \pm 0.0021$ & \\
\hline $\begin{array}{l}\text { Chromosomal abnormalities with abnormal } \\
\text { phenotypes }\end{array}$ & 5 & & 874 & $0.0082 \pm 0.0013$ & $P<0.01$ \\
\hline Trisomy $\mathrm{D}_{1}$ & 1 & & 200 & $0.0092 \pm 0.0002$ & \\
\hline Trisomy 21 & 1 & & 200 & $0.0083 \pm 0.0009$ & \\
\hline B4 short arm deletion & 1 & & 129 & $0.0081 \pm 0.0027$ & \\
\hline Cri-du-Chat & 1 & & 200 & $0.0080 \pm 0.0015$ & \\
\hline$B$ ring & 1 & & 145 & $0.0086 \pm 0.0025$ & \\
\hline \multicolumn{6}{|l|}{ Translocation carrier } \\
\hline $\mathrm{Al} / \mathrm{D}^{2}$ & 1 & & 200 & $0.0063 \pm 0.0017$ & $P>0.05$ \\
\hline
\end{tabular}

1 Not including chromatid breaks. The spontaneous background of chromosomal aberrations has been subtracted.

$246, \mathrm{XX}, \mathrm{t}(\mathrm{lq}+: \mathrm{Dq}-)$.

${ }^{3} 46, X X, t(1 q+: 2 q-)$ and $46, X Y, t(1 q+: 2 q-)$.

Chromosomal Aberrations in Irradiated Lymphocytes (Tables $I$ and $I I)$

Normal children and adults. The values for chromosome deletions per cell (del/c) after exposure to 10 rads were similar for children and adults, and the increases in values after exposure to 100 rads were also similar (Table I). Dicentrics and rings were not observed after exposure of the cells to 10 rads in children or adult control subjects, and, after 100 rads, the number of dicentrics and rings per cell $(D+R / c)$ was greater in children $(0.084 \pm 0.010)$ than in adults $(0.060 \pm 0.016)$. Values for chromosome-type breaks per cell per rad (breaks/c/r) for normal children and adults were similar (Table II).

Patients with chromosomal abnormalities. After exposure to 10 rads, values for $\mathrm{del} / \mathrm{c}$ and for $\mathrm{D}+\mathrm{R} / \mathrm{c}$ for children with chromosomal abnormalities and for normal children were similar. After exposure to 100 rads, the number of $D+R / c$ for each patient was signifcantly higher, namely $0.259 \pm 0.027$ compared with $0.084 \pm 0.010$ in cultures from control subjects. However, no change was found in the number of $\mathrm{del} / \mathrm{c}$ after the higher dose. The number of breaks $/ \mathrm{c} / \mathrm{r}$ was $0.055 \pm 0.0017$, which was significantly higher than the number $(0.0024 \pm 0.0009)$ for normal children $(P<$ $0.01)$.

There was no significant difference between the radiosensitivity of cells from patients with different types of chromosomal abnormalities (Table I).

Carriers with translocated chromosomes. After exposure to 10 rads, values for $\mathrm{del} / \mathrm{c}$ and for $\mathrm{D}+\mathrm{R} / \mathrm{c}$ for carriers with translocated chromosomes were similar to those for normal adults. After exposure to 100 rads, the number of $D+R / c$ for each subject was signifcantly higher; $0.201 \pm 0.057 \mathrm{D}+\mathrm{R} / \mathrm{c}$ occurred in cultures from carriers compared with $0.060 \pm 0.016$ in cultures from control subjects; the number of $\mathrm{del} / \mathrm{c}$ was not significantly different. The number of breaks/ $c / r$ was $0.0040 \pm 0.0018$, which was significantly higher than the $0.0020 \pm 0.0009 \mathrm{breaks} / \mathrm{c} / \mathrm{r}$ found for normal adults $(0.02>P>0.01)$.

There was no significant difference between the radiosensitivity of cells from carriers with $\mathrm{Al} / \mathrm{D}$ and $\mathrm{Al} / \mathrm{A} 2$ translocations. 
Table III. Chromosomal aberrations in fibroblasts after irradiation ${ }^{1}$

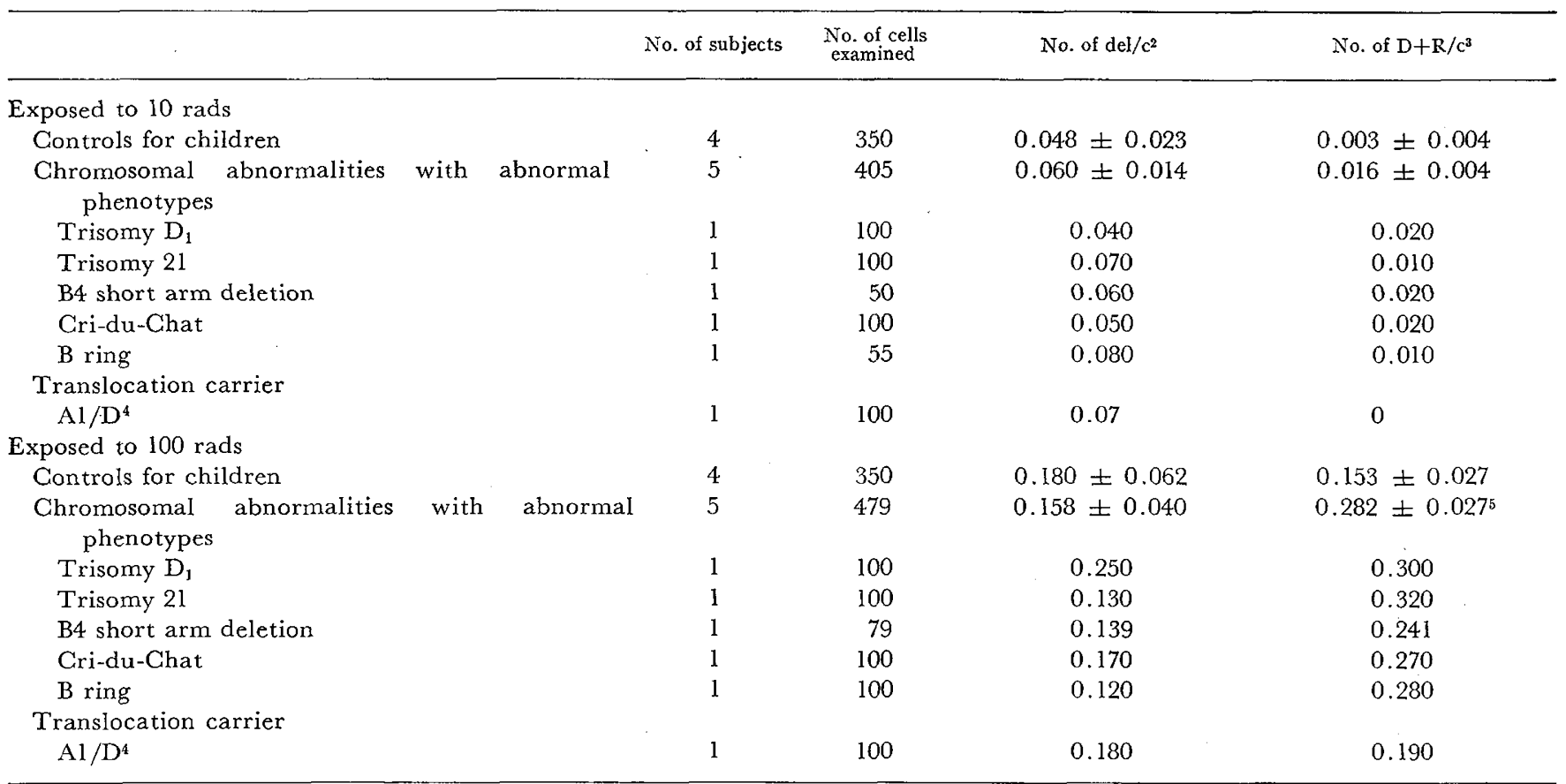

1 The spontaneous background of chromosomal aberrations has been subtracted.

$2 \mathrm{del} / \mathrm{c}$ : deletions per cell.

${ }^{3} \mathrm{D}+\mathrm{R} / \mathrm{c}$ : dicentrics and rings per cell.

${ }^{4} 46, \mathrm{XX}, \mathrm{t}(\mathrm{lq}+: \mathrm{Dq}-)$.

${ }^{5}$ Significant difference $(P<0.01)$.

Chromosomal Aberrations in Nonirradiated Fibroblasts

The number of chromosomal breaks in cultures from patients with chromosomal abnormalities and balanced translocation carriers was significantly greater than in cultures from control subjects. However, the incidence of chromosome-type breaks for patients with chromosomal abnormalities and balanced translocation carriers differed little from that for control subjects because most breaks were chromatid-type breaks.

Chromosomal Aberrations in Irradiated Fibroblasts (Tables II and III)

Normal children. The number of del/c after exposure to 10 rads was $0.048 \pm 0.023$, and, after exposure to 100 rads, the number was $0.180 \pm 0.062$. The numbers of $\mathrm{D}+\mathrm{R} / \mathrm{c}$ after exposure to 10 and to $100 \mathrm{rads}$ were $0.003 \pm 0.004$ and $0.153 \pm 0.027$, respectively. The number of breaks/c/r was $0.0049 \pm 0.0021$.

Patients with chromosomal abnormalities. After exposure to $10 \mathrm{rads}$, values for $\mathrm{del} / \mathrm{c}$ and $\mathrm{D}+\mathrm{R} / \mathrm{c}$ were similar to those for normal children. After exposure to
100 rads, the number of $D+R / c$ for each patient was significantly higher than that for control subjects; $0.282 \pm 0.027 \mathrm{D}+\mathrm{R} / \mathrm{c}$ were found in cultures from these patients compared with $0.153 \pm 0.027$ in those from control subjects. No significant difference was found in the number of del/c at this higher dose. The number of breaks/c/ $\mathrm{r}$ was $0.0082 \pm 0.0013$, which was significantly higher than the number $(0.0049 \pm 0.0021)$ found for normal children $(P<0.01)$.

Carrier with translocated chromosome. After exposure to $10 \mathrm{rads}$, values for $\mathrm{del} / \mathrm{c}$ and $\mathrm{D}+\mathrm{R} / \mathrm{c}$ for this case were similar to those for normal children. (Values for normal adults were not available.) After exposure to 100 rads, the number of $D+R / c$ was 0.190 , which was higher than the $0.153 \pm 0.027$ found for normal children; values for $\mathrm{del} / \mathrm{c}$ and chromosome-type breaks $/ \mathrm{c} / \mathrm{r}$ for this $\mathrm{Al} / \mathrm{D}$ translocation carrier were similar to values for normal children.

\section{Discussion}

These results cannot always be compared directly with those reported by Dekaban et al. [6], Chudina [3], 
Sasaki and Tonomura [16], and Sasaki et al. [17] because most of those studies were limited to cultured lymphocytes from patients with Down's syndrome. Chudina reported on lymphocytes irradiated within 4 hr of the termination of the culture, when chromatid breaks are the main aberrations. Dekaban et al. studied lymphocytes after $72 \mathrm{hr}$ in culture when the cells were in their second postirradiation division. Induced chromosomal aberrations should be evaluated in the first postirradiation division because some abnormal nuclei may not survive to a second postirradiation division. Sasaki and Tonomura measured chromosomal damage in metaphases in the first postirradiation division from lymphocyte cultures of patients with Down's syndrome irradiated at various doses. Sasaki et al. [17] examined chromosomal radiosensitivity of blood samples obtained from patients with various types of chromosomal abnormalities besides Down's syndrome. They reported that the chromosomal radiosensitivity was consistently higher in cultured lymphocytes that were trisomic for the whole or a part of a chromosome than in cultured lymphocytes with normal karyotype, but that it was not significantly influenced by the monosomic conditions and reciprocal translocation. They did not examine radiosensitivity of cultured fibroblasts.

Cultures of both fibroblasts and lymphocytes were investigated in this study; irradiated lymphocytes were harvested at $52 \mathrm{hr}$ of culture and fibroblast cultures were harvested $24 \mathrm{hr}$ after irradiation, so that each included first postirradiation divisions [1, 11]. Two different age groups (children and adults) were used as control subjects because the age of the subject may affect the frequency of induced chromosomal aberrations [16]. In addition, these groups served as controls for the patients with abnormal chromosomes who were children and for the balanced translocation carriers who were all adults.

The number of breaks/c/r in cultured lymphocytes seemed higher for children than for adults but the difference was not statistically significant.

The number of breaks $/ \mathrm{c} / \mathrm{r}$ proved to be a valuable measure of radiosensitivity for the relatively low doses of radiation used in this study. The number of breaks $/ c / r$ in cultures of both lymphocytes and fibrohlasts from patients with chromosomal abnormalities and in those from the balanced translocation carriers was significantly higher than in those from normal control subjects. However, the frequency of chromosometype breaks was lower than that which we had found in patients with Fanconi's anemia [9]. In addition to the number of breaks/c/r, the numbers of $\mathrm{del} / \mathrm{c}$ and of $\mathrm{D}+\mathrm{R} / \mathrm{c}$ were also studied. On the whole, the number of $\mathrm{D}+\mathrm{R} / \mathrm{c}$ was a more sensitive indicator of irradiation than was the number of $\mathrm{del} / \mathrm{cell}$. It was interesting to note that the level of chromosomal aberrations of the exchange type increased although the level of simple chromosome deletions did not; similar findings were reported by Sasaki and Tonomura [16] in cells from patients with Down's syndrome. There is little variation between radiosensitivity in different abnormalities but all are significantly higher than the normal.

In order to determine whether the increased chromosomal radiosensitivity in patients and carriers was attributable to the unusual involvement of a certain chromosome, most probably an extra or translocated chromosome, the frequencies of chromosomes involved in these aberrations were studied. The differences between observed and expected frequencies, however, were not significant.

Comparison of chromosomal damage caused by $\mathrm{x}$ rays usually revealed greater radiosensitivity in cultured fibroblasts than in lymphocytes. In a few cases there was relatively more breakage in cultured lymphocytes than in fibroblasts. This may be because the abnormal patients often had received several diagnostic x-rays. There may also be differences in radiosensitivity between fibroblasts obtained from different sites in patients, carriers, and control subjects.

This study shows that cells with abnormalities such as trisomy, deletions, rings, and translocations all have higher chromosomal radiosensitivity as measured by the frequency of chromosomal aberrations after two unit doses of $\gamma$ rays. This evidence is of interest because of the high incidence of leukemia and other malignant diseases in patients with some chromosomal abnormalities such as Down's syndrome and chromosomal breakage syndrome [7] and because of the susceptibility of cultured fibroblasts from patients with Down's syndrome and trisomy 18 to SV40 transformation $[18,19]$. Therefore, it seems that cells from patients with chromosomal abnormalities, and even those from balanced translocation carriers, have particularly high sensitivity to chromosomal damage by mutagenic agents. It is strongly advised that such individuals be protected from unnecessary $\mathrm{x}$-ray examination.

\section{Summary}

This paper reports in vitro tests of chromosomal radiosensitivity in five children and three adults with normal karyotypes as control subjects, in seven patients 
(children) with chromosomal abnormalities, and in six translocation carriers (adults). Peripheral blood samples from each individual and skin fibroblast cultures from 10 of these individuals were irradiated with 10 and 100 rads. Nonirradiated duplicate cultures were used as controls. Blood cultures were harvested after $52 \mathrm{hr}$ of incubation and fibroblast cultures were harvested $24 \mathrm{hr}$ after irradiation. The frequency of chromosomal breakage caused by irradiation is the difference between the value for irradiated samples and that for nonirradiated samples.

After irradiation, the number of breaks/cell/rad in cultures from patients with chromosomal abnormalities and balanced translocation carriers was significantly greater than that for controls. After irradiation with 100 rads, the number of dicentrics and rings per cell was significantly greater for both patients and carriers of chromosomal abnormalities than for controls. Therefore, chromosomes of cells from patients with chromosomal abnormalities and from translocation carriers were significantly more radiosensitive in vitro than those from controls.

\section{References and Notes}

1. Atkins, L., ANd Santesson, B.: Chromosome DNA synthesis in cultured normal human female skin cells. Hereditas, 55: 39 (1966).

2. BASRUR, P. K., BASRUR, V. R., AND GILman, J. P. W.: A simple method for short term cultures from small biopsies. Exp. Cell Res., 30: 229 (1963).

3. Chudina, A. P.: A study of the radiosensitivity of chromosomes in normal persons and in cases of Down's syndrome. Genetika, 4: 99 (1968).

4. Conen, P. E., ANd ERKMan, B.: Combined mongolism and leukemia. Amer. J. Dis. Child., 112: 429 (1969).

5. Cunningham, J. R., Bruce, W. R., and WebB, H. P.: A convenient ${ }^{137} \mathrm{Cs}$ unit for irradiating cell suspensions and small laboratory animals. Phys. Med. Biol., 10: 381 (1965).

6. Dekaban, A. S., Thron, R., and Steusing, J. K.: Chromosomal aberrations in irradiated blood and blood cultures of normal subjects and of selected patients with chromosomal abnormality. Radiation Res., 27: 50 (1966).

7. German, J.: Chromosomal breakage syndromes. Birth Defects, 5: 117 (1969).

8. Harnden, D. G., Langlands, A. D., McBeath, S., O'Riordan, M., AND FAED, M. J. W.: The frequency of constitutional chromosome abnormalities in patients with malignant disease. Eur. J. Cancer, 5: 605 (1969).

9. Higurashi, M., AND Conen, P. E.: In vitro chromosomal radiosensitivity in Fanconi's anemia. Blood, 38: 336 (1971).

10. Jackson, E. W., Turner, J. H., Klauber, M. R., and Norris, F. D.: Down's syndrome: variation of leukaemia occurrence in institutionalized populations. J. Chronic Dis., 21: 247 (1968).

11. KAO, F., AND PUCK, T. T.: Genetics of somatic mammalian cells: linkage studies with human-Chinese hamster cell hybrids. Nature, 228: 329 (1970).

12. KRrvir, W., AND Good, R. A.: Simultaneous occurrence of mongolism and leukemia: report of nationwide survey. Amer. J. Dis. Child., 94: 289 (1957).

13. Miller, R. W.: Down's syndrome (mongolism), other congenital malformations and cancer among the sibs of leukemic children. New Engl. J. Med., 268: 393 (1963).

14. Miller, R. W., and Fraument, J. F., Jr.: Down's syndrome and neonatal leukaemia. Lancet, $i i$ : 404 (1968).

15. Moorhead, P. S., Nowell, P. C., Mellman, W. J., Battips, D. M., AND Hungerford, D. A.: Chromosome preparations of leukocytes cultured from human peripheral blood. Exp. Cell Res., 20: 613 (1960).

16. SAsaki, M. S., and Tonomura, A.: Chromosomal radiosensitivity in Down's syndrome. Jap. J. Hum. Genet., 14: 81 (1969).

17. Sasakr, M. S., Tonomura, A., and Matsubara, S.: Chromosomal constitution and its bearing on the chromosomal radiosensitivity in man. Mutat. Res., 10:617 (1970).

18. Todaro, G. J., Green, H., and Swift, M. R.: Susceptibility of human diploid fibroblast strains to transformation by SV40 virus. Science, 153: 1252 (1966).

19. Todaro, G. J., and Martin, G. M.: Increased susceptibility of Down's syndrome fibroblasts to transformation by SV40. Proc. Soc. Exp. Biol. Med., 124: 1232 (1967).

20. Warkany, J., Schubert, W. K., and Thompson, J. N.: Chromosome analysis in mongolism associated with leukemia. New Engl. J. Med., 268: 1 (1963).

21. Victoreen Instruments Division, Cleveland, Ohio.

22. Informed consent was obtained from each adult subject and from the parents of each child in the study.

23. Blood samples were obtained from samples collected for preoperative examinations. Skin samples were taken during appendectomy or herniorrhaphy.

24. Each sample was collected for this study.

25. This work was supported by the Ontario Cancer Treatment and Research Foundation.

26. Requests for reprints should be addressed to: Макото Hrgurashi, M.D., Division of Genetics, Department of Pediatrics, Kyorin University, School of Medicine, Tokyo, Japan.

27. Accepted for publication November 18, 1971. 